\title{
Variabilidade espacial da produtividade do feijoeiro correlacionada com atributos químicos de um Latossolo Vermelho Distroférrico sob sistema de semeadura direta
}

\author{
Flávio Carlos Dalchiavon ( $\left(^{*}\right)$; Morel Passos Carvalho (2); Onã Silva Freddi (3); \\ Marcelo Andreotti ( ${ }^{2}$ ); Rafael Montanari $\left({ }^{4}\right)$ \\ (') FEIS/UNESP, Programa de Pós-Graduação em Agronomia, Caixa Postal 31, 15385-000 Ilha Solteira (SP), Brasil. \\ (2) FEIS/UNESP, Departamento de Fitossanidade, Engenharia Rural e Solos, Ilha Solteira (SP), Brasil. \\ (3) Universidade Federal de Mato Grosso (UFMT), Instituto de Ciências Agrárias e Ambientais, Av. Alexandre Ferronato, 1200, \\ 78550-000 Sinop (MT), Brasil. \\ (4) Universidade Estadual de Mato Grosso do Sul (UEMS), Rodovia Aquidauana km 12, 79200-000 Aquidauana (MS), Brasil. \\ (*) Autor correspondente: fcdalchiavon@hotmail.com
}

Recebido: 26/nov./2010; Aceito: 5/jul./2011

\section{Resumo}

O feijão, importante fonte proteica, é um alimento muito comum na dieta da população dos países latino-americanos, sendo o Brasil maior produtor mundial deste legume. Nacionalmente, seu cultivo no sistema de semeadura direta tem crescido ano após ano. Em 2002, foi avaliada a variabilidade espacial do feijoeiro, em função dos atributos químicos de um Latossolo Vermelho Distroférrico no sistema de semeadura direta, em Selvíria (MS) no Cerrado Brasileiro. O objetivo do presente estudo foi selecionar, entre os atributos do solo pesquisado, aquele com a melhor correlação, linear e espacial, para explicar a variabilidade da produtividade do feijoeiro. Foi instalada uma rede amostral, para a coleta de dados do solo e das plantas, com 135 pontos amostrais, em uma área de $7500 \mathrm{~m}^{2}$. A produtividade de grãos de feijão (PG) representou o atributo da planta, enquanto os do solo foram: P, MO, pH, K, Ca, Mg, H+Al, S, T e o V\%. Estabeleceram-se correlações lineares, simples e múltiplas, entre a PG e os atributos do solo. Foram modelados semivariogramas para todos os atributos, obtendo-se as respectivas krigagens e validações cruzadas. Também foram estabelecidas as co-krigagens entre a PG e os atributos do solo. Em relação à produtividade de grãos de feijão, $22 \%$ da sua variação foram atribuídos à variação nos atributos químicos do solo. Tanto linear quanto espacialmente, o pH do solo foi bom indicador da produtividade de grãos de feijão quando cultivado sob sistema de semeadura direta.

Palavras-chave: fertilidade do solo, geoestatística, manejo e conservação do solo, Phaseolus vulgaris L.

\section{Spatial variability of the bean yield correlated with chemical attributes of a Typic acrustox under no-tillage system}

\footnotetext{
Abstract

The bean, an important source of protein, is a very important and nutritive food in the diet of Latin-American population, being Brazil the larger world producer of this vegetable. Its cultivation under no-tillage system has increased year after year. In 2002, the spatial variability of the bean yield was evaluated under no-tillage system in a Dystropherric Red Latosol (Typic Acrustox) of the Brazilian Savannah. The main purpose of this study was to select the soil attribute that have the best spatial and linear correlation with bean yield. A geostatistical grid, with 135 sampling points, was installed to collect the soil and plant data in an area of 7,500 $\mathrm{m}^{2}$. The bean grains productivity (GP) was the plant attribute, while the soil ones were: $\mathrm{P}, \mathrm{OM}$, $\mathrm{pH}, \mathrm{K}$, $\mathrm{Ca}, \mathrm{Mg}, \mathrm{H}+\mathrm{Al}$, S, CEC and V\%. Linear relationships, simple and multiple, were calculated between the GP and the soil attributes. The semivariograms were adjusted for all the attributes, obtaining krigings and cross-validations and also evaluating the cokrigings between the GP and the soil attributes. In relation to the bean grain yield, around $22 \%$ of its variation was attributed to the variation in the soil chemical attributes. From both linear and spatial view points, the soil pH was a good indicator of the bean grains yield under no-tillage system.
}

Key words: soil fertility, geostatistical, soil management and conservation, Phaseolus vulgaris L. 


\section{INTRODUÇÃO}

A planta do feijoeiro produz um legume reconhecidamente uma excelente fonte proteica de carboidratos, vitaminas, minerais, fibras e compostos fenólicos que podem reduzir a incidência de doenças, além de ser um dos mais importantes componentes da dieta alimentar do brasileiro. Paralelamente a este fato, o feijão é um dos produtos agrícolas de maior importância econômico-social, devido principalmente à máo de obra empregada durante o ciclo da cultura e o número de cultivos possíveis nas diversas regióes produtoras do país.

Segundo Conab (2010), considerando-se as três safras, estima-se que a área total cultivada com feijão no Brasil (maior produtor mundial do grão), na safra de 2009/2010 ficou em torno de 3,58 milhōes de hectares, resultando em uma produçáo nacional de 3,27 milhôes de toneladas, com produtividade média de $913 \mathrm{~kg} \mathrm{ha}^{-1}$. Especificamente para o Estado de Mato Grosso do Sul, a produtividade média foi de $1456 \mathrm{~kg} \mathrm{ha}^{-1}$.

O cultivo do feijoeiro em sistema de semeadura direta (SD) merece destaque em virtude dos inúmeros benefícios que podem decorrer de seu uso, tanto econômicos quanto ambientais. De acordo com Nicolodi et al. (2008), os benefícios para o solo são: aumento dos teores de matéria orgânica (MO) e de nutrientes, diminuição da toxidez do $\mathrm{Al}$ às plantas, melhoria da estrutura e da capacidade de retençáo de água, aumento da fertilidade na camada superficial e preservação das relaçóes microbiológicas construídas com o tempo de cultivo, principalmente pelo não revolvimento e a consequente manutenção dos resíduos das culturas na superfície. Tendo em vista tais benefícios, vários estudos têm sido desenvolvidos com a cultura do feijoeiro em SD. Fageria e Stone (2004) pesquisaram a produtividade de feijão com aplicação de calcário e zinco e verificaram incremento significativo na produtividade com a aplicação de calcário. SAntos et al. (2004) avaliaram o comportamento de cultivares de feijoeiro-comum com diferentes palhadas no solo e comprovaram que no solo com pequena quantidade de palha, o plantio direto sobre resteva do pousio propiciou maior rendimento de grãos. BARBosA et al. (2010) pesquisaram nitrogênio em cobertura e molibdênio foliar no feijoeiro de inverno e averiguaram efeito significativo das doses de nitrogênio sobre alguns dos componentes de produção.

Por outro lado, o processo de modernizaçáo e racionalização da agricultura constitui fator importante para o aumento da produtividade. O custo crescente dos insumos agrícolas exige, cada vez mais, a adoção de técnicas de cultivos adequadas na produção das culturas anuais. Desta forma, há tendência de integração de diversas fontes de dados, a fim de melhor gerenciar a produção agrícola, ocorrida em virtude do reconhecimento cada vez maior de que as culturas e os solos não devem ser manejados individualmente e de forma homogênea. Grego e VieIra (2005) afirmaram que a aplicação de tecnologia associada à variabilidade espacial se faz necessária, sobretudo na pesquisa agrícola, que estuda o solo e sua capacidade produtiva. Reforçando esta questáo, Molın (2000) salientou que a agricultura de precisão surgiu como um elenco de tecnologias e procedimentos utilizados para que os sistemas de produção agrícolas sejam otimizados, tendo como elemento-chave, o gerenciamento da variabilidade espacial da produção e os fatores a ela relacionados.

Neste contexto, o objetivo deste estudo foi selecionar entre os atributos do solo avaliados, aquele com a melhor correlação, linear e espacial, para explicar a variabilidade da produtividade de grãos de feijão de inverno sob sistema plantio direto no Cerrado brasileiro.

\section{MATERIAL E MÉTODOS}

O trabalho foi desenvolvido no município de Selvíria (MS), entre as latitudes de $20^{\circ} 18^{\prime} 05^{\prime \prime} \mathrm{S}$ e $20^{\circ} 18^{\prime} 28^{\prime \prime} \mathrm{S}$ e as longitudes de $52^{\circ} 39^{\prime} 02^{\prime \prime W}$ e $52^{\circ} 40^{\prime} 28^{\prime \prime W}$. A precipitação pluvial média anual local é de $1300 \mathrm{~mm}$, enquanto a temperatura média do ar, de $23,7{ }^{\circ} \mathrm{C}$. Conforme preceitos de Köppen referidos por Vianello e Alves (2004), o clima regional é o tropical úmido megatérmico (Aw), com estação chuvosa no veráo e seca no inverno. O solo da área experimental é Latossolo Vermelho Distroférrico (EMBrapa, 2006) irrigado por pivô central, cuja caracterização inicial da fertilidade, para a camada de $0-0,20 \mathrm{~m}$, possui os seguintes valores: $\mathrm{pH}\left(\mathrm{CaCl}_{2}\right)=5,0 ; \mathrm{MO}=27 \mathrm{~g} \mathrm{dm}^{-3}$; $\mathrm{P}$ (resina) $=18 \mathrm{mg} \mathrm{dm}^{-3} ; \mathrm{K}, \mathrm{Ca}, \mathrm{Mg}$ e $\mathrm{H}+\mathrm{Al}=4,1 ; 22$; 15 e $36 \mathrm{mmol}_{\mathrm{c}} \mathrm{dm}^{-3}$, respectivamente; com $\mathrm{V}=53,3 \%$. $\mathrm{Na}$ figura 1, estáo indicadas as precipitaçóes pluviais e temperaturas médias durante o período de cultivo.

A área experimental já era cultivada há seis anos sob $\mathrm{SD}$, com a sucessão milho/feijão. Assim, o cultivo do feijoeiro ocorreu com a dessecação da cultura antecessora (milho) e das plantas daninhas remanescentes com a aplicação de $1,8 \mathrm{~kg} \mathrm{ha}^{-1}$ (i.a.) do herbicida glifosato, entre os dias 15 e 18/4/2002. Em 6/5/2002 foi semeada a cultivar de feijoeiro IAC Carioca Eté, no espaçamento de $0,50 \mathrm{~m}$ entre linhas, com 15 sementes $\mathrm{m}^{-1}$, proporcionando densidade média de 12 plantas $\mathrm{m}^{-1}$. Na adubação de semeadura foram utilizados $200 \mathrm{~kg} \mathrm{ha}^{-1}$ da fórmula 08-28-16 (NPK). Na adubação de cobertura realizada 20 dias após a emergência das plântulas, foram aplicados $200 \mathrm{~kg} \mathrm{ha}^{-1} \mathrm{da}$ fórmula 20-00-20 (NPK). As práticas de manejo da cultura foram procedidas homogeneamente em toda a área experimental. A colheita da cultura foi efetuada manualmente aos 96 dias após a emergência das plantas (9/8/2002) e o material proveniente de cada ponto amostral foi posto para secar à sombra, sendo posteriormente trilhado, peneirado e pesado para se obter a produtividade de grãos. 


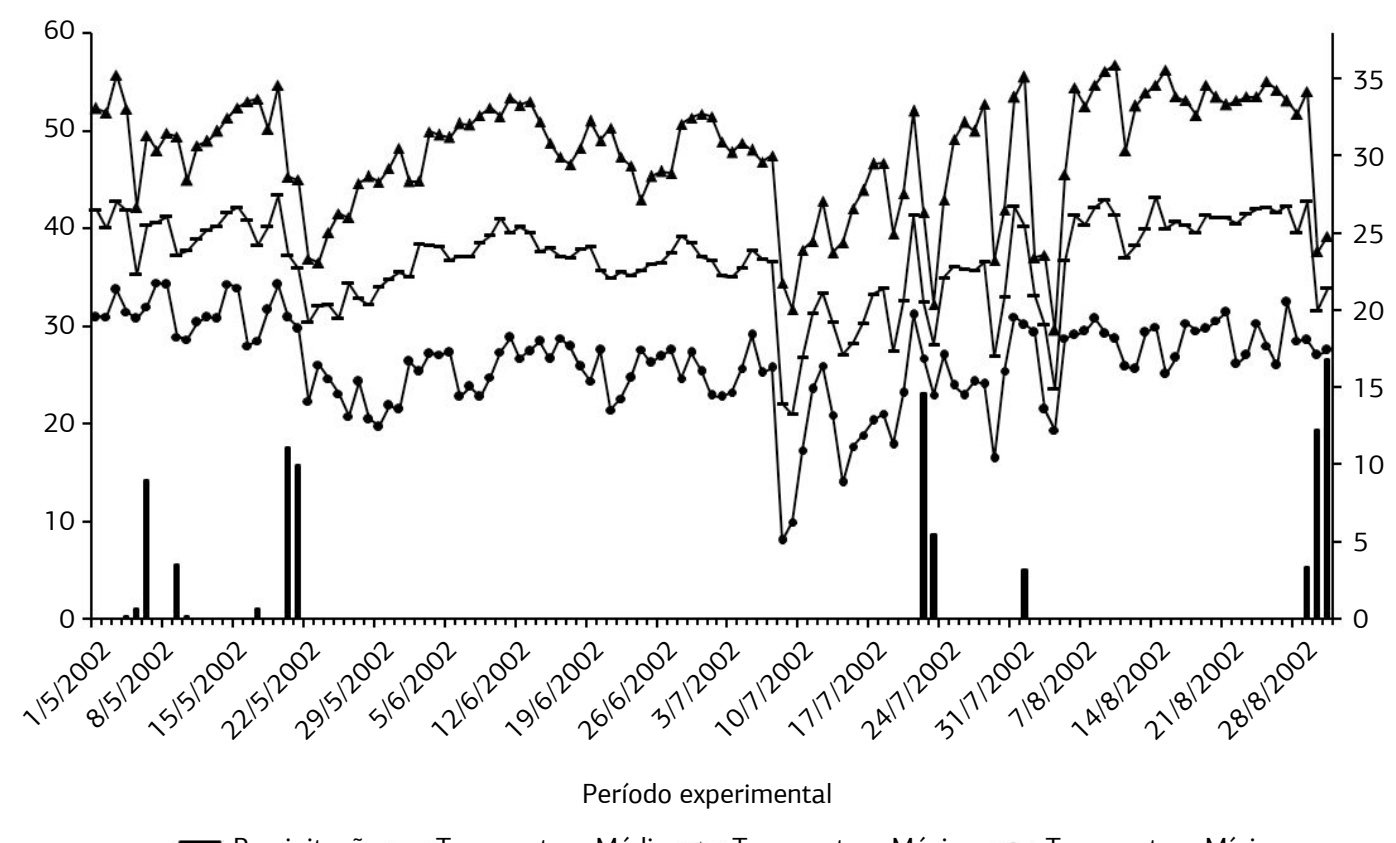

- Precipitação — Temperatura Média $₫$ Temperatura Máxima $\rightarrow$ - Temperatura Mínima

Figura 1. Precipitação pluvial e temperatura do ar (mínima, máxima e média) durante o período de maio a agosto de 2002.

$\mathrm{Na}$ alocação da malha amostral, estabelecida entre dois terraços, foram definidas as direções x e y do sistema de coordenadas cartesianas. Para tanto, foi utilizado um nível ótico comum, efetuando-se o estaqueamento global da malha experimental logo após a semeadura da cultura. A grande malha experimental foi constituída de cinco transeçôes paralelas ao eixo $\mathrm{x}$, contendo 15 pontos de amostragem cada uma, resultando em 75 pontos amostrais, com espaçamento entre pontos de $10 \mathrm{~m} \times 10 \mathrm{~m}$, em uma área total de $7500 \mathrm{~m}^{2}(150 \mathrm{~m}$ x $50 \mathrm{~m})$. Entretanto, foram alocadas por sorteios, dentro da grande malha, mais quatro transeçôes de pontos amostrais, visando detalhar o estudo da dependência espacial dos dados para condiçóes menores do que $10 \mathrm{~m}$. Cada pequena malha ficou posicionada entre quatro pontos amostrais da grande malha, com um ponto no seu centro e mais 14 pontos; sete destes ficaram distribuídos no segundo quadrante e o restante no quarto quadrante da pequena malha, com espaçamento entre pontos de $2,5 \mathrm{~m} \mathrm{x} 2,5 \mathrm{~m}$. Cada uma delas adicionou mais 15 pontos amostrais, ficando o total de $135(75+60)$.

Foram avaliados atributos do solo e das plantas, individualmente coletados no entorno de cada ponto amostral da malha experimental. Os atributos do solo avaliados foram: teores de fósforo $(\mathrm{P})$, matéria orgânica $(\mathrm{MO})$, valores de $\mathrm{pH}\left(\mathrm{CaCl}_{2}\right)$, teores de potássio $(\mathrm{K})$, cálcio $(\mathrm{Ca})$, magnésio $(\mathrm{Mg})$, acidez potencial $(\mathrm{H}+\mathrm{Al})$, soma de bases $(\mathrm{S})$, capacidade de troca catiônica $(\mathrm{T})$ e a saturação por bases (V\%). Para tal, foi coletada uma única amostra simples de solo, com trado de caneca (diâmetro $=0,08 \mathrm{~m}$, altura $=0,20 \mathrm{~m}$, volume $\left.=0,001 \mathrm{~m}^{3}\right)$, em cada um dos 135 locais de coleta dos dados, na profundidade de 0 a $0,20 \mathrm{~m}$, e destinada à análise química para fins de fertilidade, realizada conforme Cantarella et al. (2001).

Foi avaliada a produtividade de grãos de feijão (PG), sendo esta corrigida para a condiçâo de umidade de 13\% (base úmida) através da obtenção de duas leituras do valor da umidade dos grâos, e calculada segundo a seguinte expressão:

$P_{c}=P \cdot\left[\left(1-u_{d}\right) /\left(1-u_{o b}\right)\right]$

onde: $\mathrm{P}_{\mathrm{c}}$ representou a massa corrigida dos grãos de feijão ( $\left.\mathrm{kg} \mathrm{ha}^{-1}\right)$; P representou a massa de campo (não corrigida) dos grãos de feijão $\left(\mathrm{kg} \mathrm{ha}^{-1}\right)$; $\mathrm{u}_{\mathrm{d}}$ representou a umidade desejada como padrão (13\%), e $\mathrm{u}_{\mathrm{ob}}$ representou a média das duas umidades observadas para cada ponto amostral (\%). A umidade dos grãos foi obtida através de aparelho próprio, de leitura digital e funcionamento a pilha (Marca Dickey-John modelo Multi-Grain). A PG ( $\left.\mathrm{kg} \mathrm{ha}^{-1}\right)$ foi obtida através da coleta das plantas no entorno de cada ponto amostral, com área útil de $4 \mathrm{~m}^{2}(2 \mathrm{~m} \times 2 \mathrm{~m})$, com a alocação do ponto posicionado no seu centro, entre quatro linhas de semeadura.

A análise estatística dos atributos estudados foi constituída da análise descritiva inicial, estudo de regressão linear e análise geoestatística. Utilizou-se o SAS (SCHLotzhAVER e LitTel, 1997) para calcular a média, mediana, valor mínimo e máximo, desvio-padrão, coeficiente de variação, curtose, assimetria e distribuição de frequência. Para testar a hipótese da normalidade, ou da lognormalidade dos dados, foi utilizado o teste de Shapiro e Wilk (1965) a 1\%. Assumiu-se a princípio, a não transformação logarítmica 
dos atributos com distribuiçáo de frequência lognormal, única e exclusivamente tendo como objetivo de se trabalhar com os dados originais deles. A correçâo dos outliers foi procedida mediante o cálculo da média aritmética dos valores dos pontos vizinhos na malha de estudo.

Foi montada a matriz de correlação de Pearson objetivando efetuar as correlaçôes lineares para as combinaçōes, duas a duas, entre todos os atributos estudados, assim como apresentar as análises de regressóes para os pares de maior interesse. Selecionaram-se aqueles de maior correlaçáo linear e que, portanto, poderiam apresentar semivariograma cruzado e a consequente co-krigagem. Com o auxílio do pacote computacional Gamma Design Software $7.0\left(\mathrm{Gs}^{+}, 2004\right)$ foi efetuada a análise da dependência espacial, para cada atributo estudado, pela aplicação da hipótese intrínseca na modelagem do semivariograma. O ajuste do melhor modelo foi efetuado segundo: 1- menor soma dos quadrados dos desvios (RSS); 2- maior coeficiente de determinação $\left(\mathrm{r}^{2}\right)$; 3- maior valor do avaliador da dependência espacial (ADE), conforme Dalchiavon et al. (2011). Entretanto, para os atributos (ATR) com tendência no semivariograma, retirou-se essa tendência por meio da técnica da regressão múltipla polinomial, conforme preceitos de Davis (1986). Assim, ficaram precedidos do símbolo \# quando referidos na análise semivariográfica e na validação cruzada (\#ATR). Já quando referidos no mapa de krigagem e/ou co-krigagem ficaram precedidos por $£$ (£ATR).

A decisão final do modelo que representou o ajuste foi realizada pela validação cruzada, assim como para a definição do tamanho da vizinhança que proporcionou a melhor malha de krigagem e/ou co-krigagem, realizadas por meio da krigagem em blocos. Para cada atributo, foram relacionados o efeito pepita $\left(C_{o}\right)$, o alcance $\left(A_{o}\right)$ e o patamar $\left(\mathrm{C}_{\mathrm{o}}+\mathrm{C}\right)$. A análise do avaliador da dependência espacial (ADE) foi efetuada conforme a Equação 2.

$A D E=(C /(C+C o)) \times 100$

Em que: $\mathrm{ADE}$ é o avaliador da dependência espacial, $\mathrm{C}$ é a variância estrutural e $\mathrm{C}+\mathrm{C}_{\mathrm{o}}$ é o patamar. Desta forma, a interpretação proposta para $\mathrm{ADE}$ foi: a) $\mathrm{ADE} \leq 25 \%$, indicou variável espacial fracamente dependente; b) $25 \%<$ $\mathrm{ADE} \leq 75 \%$, indicou variável espacial medianamente dependente; c) $\mathrm{ADE}>75 \%$, indicou variável espacial fortemente dependente, conforme sugestôes de CAMBARDELla et al. (1994), modificadas pelo $\mathrm{Gs}^{+}$(2004).

\section{RESULTADOS E DISCUSSÃO}

Os atributos pesquisados (Tabela 1) tiveram baixa variabilidade dos dados para o $\mathrm{pH}$, com coeficiente de variação $(\mathrm{CV})$ de $7,3 \%$; média variabilidade para a matéria orgânica e saturaçáo por bases $(\mathrm{CV}=13,8-13,9 \%)$; alta variabilidade para a produtividade de gráos, acidez potencial e capacidade de troca cationica (CV = 20,0-20,4\%), e muito alta variabilidade para os demais atributos $(\mathrm{CV}=30,4-64,5 \%)$ (Pimentel-Gomes e Garcia, 2002). A elevada variabilidade dos nutrientes no solo é comum em SD pelo efeito localizado de adubaçóes, principalmente no caso do P, com baixa mobilidade no solo. Com relaçáo ao $\mathrm{K}$, como a cultura antecessora foi o milho em espaçamento de $0,90 \mathrm{~m}$, a adubação também pode interferir nos resultados, pois mesmo utilizando trado de caneca, na coleta das amostras podem ocorrer erros amostrais por efeito de linhas e entrelinhas de culturas adubadas anteriormente na área. Desta alta variabilidade surge a necessidade de técnicas

Tabela 1. Análise da estatística descritiva da produtividade do feijão e de atributos químicos de um Latossolo Vermelho Distroférrico sob plantio direto.

\begin{tabular}{|c|c|c|c|c|c|c|c|c|c|c|}
\hline \multirow{3}{*}{ Atributo } & \multicolumn{10}{|c|}{ Medidas estatísticas descritivas } \\
\hline & \multirow[t]{2}{*}{ Média } & \multirow[t]{2}{*}{ Mediana } & \multicolumn{2}{|c|}{ Valor } & \multirow{2}{*}{$\begin{array}{l}\text { Desvio- } \\
\text { padrão }\end{array}$} & \multicolumn{3}{|c|}{ Coeficiente } & \multicolumn{2}{|c|}{$\begin{array}{l}\text { Probabilidade } \\
\text { do teste }\end{array}$} \\
\hline & & & Mínimo & Máximo & & Variação (\%) & Curtose & Assimetria & $\operatorname{Pr}<W$ & DF \\
\hline \multicolumn{11}{|l|}{ Atributo da planta } \\
\hline PG $\left(\mathrm{kg} \mathrm{ha}^{-1}\right)$ & 3044 & 3051 & 1405 & 4647 & 618,1 & 20,3 & $-0,060$ & $-0,028$ & 0,838 & NO \\
\hline \multicolumn{11}{|c|}{ Atributos químicos do solo } \\
\hline$P\left(\mathrm{mg} \mathrm{dm}^{-3}\right)$ & 28,4 & 23,0 & 4,0 & 97,0 & 18,33 & 64,5 & $-0,309$ & 0,010 & 0,637 & LN \\
\hline $\mathrm{MO}\left(\mathrm{g} \mathrm{dm}^{-3}\right)$ & 25,3 & 25,0 & 18,0 & 34,0 & 3,51 & 13,9 & $-0,744$ & 0,148 & 0,014 & IN \\
\hline $\mathrm{pH}$ & 5,07 & 5,10 & 4,20 & 6,20 & 0,371 & 7,3 & 0,230 & 0,350 & 0,072 & NO \\
\hline $\mathrm{K}\left(\mathrm{mmol}_{\mathrm{c}} \mathrm{dm}^{-3}\right)$ & 5,05 & 5,00 & 1,30 & 9,20 & 1,943 & 38,5 & $-1,012$ & 0,062 & 0,007 & IN \\
\hline $\mathrm{Ca}\left(\mathrm{mmol}_{\mathrm{c}} \mathrm{dm}^{-3}\right)$ & 28,8 & 28,0 & 10,0 & 53,0 & 9,31 & 32.3 & $-0,655$ & 0,243 & 0,050 & NO \\
\hline $\mathrm{Mg}\left(\mathrm{mmol}_{\mathrm{c}} \mathrm{dm}^{-3}\right)$ & 18,0 & 18,0 & 6,0 & 34,0 & 5,75 & 31,9 & $-0,344$ & 0,229 & 0,203 & NO \\
\hline $\mathrm{H}+\mathrm{Al}\left(\mathrm{mmol}_{\mathrm{c}} \mathrm{dm}^{-3}\right)$ & 27,6 & 27,0 & 18,0 & 42,0 & 5,52 & 20,0 & $-0,147$ & 0,649 & $2.10^{-4}$ & IN \\
\hline $\mathrm{S}\left(\mathrm{mmol}_{\mathrm{c}} \mathrm{dm}^{-3}\right)$ & 52,04 & 51,20 & 17,70 & 97,40 & 15,816 & 30,4 & $-0,361$ & 0,257 & 0,260 & NO \\
\hline $\mathrm{T}\left(\mathrm{mmol}_{\mathrm{c}} \mathrm{dm}^{-3}\right)$ & 79,83 & 78,40 & 35,71 & 120,60 & 16,250 & 20,4 & $-0,178$ & 0,004 & 0,797 & NO \\
\hline V\% & 64,0 & 64,0 & 41,0 & 83,0 & 8,82 & 13,8 & $-0,344$ & $-0,354$ & 0,058 & NO \\
\hline
\end{tabular}

$\mathrm{PG}=$ produtividade de grãos do feijăo; $\mathrm{P}, \mathrm{MO}, \mathrm{pH}, \mathrm{K}, \mathrm{Ca}, \mathrm{Mg}, \mathrm{H}+\mathrm{Al}, \mathrm{S}, \mathrm{T}, \mathrm{V} \%$ são, respectivamente, fósforo, matéria orgânica, potencial hidrogeniônico, potássio, cálcio, magnésio, acidez potencial, soma de bases, capacidade de troca catiônica e saturaçáo por bases. DF = distribuição de frequência, sendo NO, LN e IN, respectivamente, tipo normal, lognormal e indefinida. 
mais apuradas como a agricultura de precisão que levam em consideração justamente esse efeito do erro amostral de coleta de solo.

No geral, os dados do presente estudo (Tabela 1) propiciaram tendência à variabilidade de forma análoga aos de Cavalcante et al. (2007), que em um Latossolo Vermelho Distrófico de Selvíria (MS) estudaram a variabilidade espacial de atributos químicos do solo em áreas de vegetaçáo natural, pastagem, plantio direto e plantio convencional; nas áreas de plantio direto e convencional, adotou-se a rotação de culturas com feijão, milho, soja e aveia preta, e constataram as maiores variabilidades nos dados de P e K. Da mesma forma, foram semelhantes à pesquisa de AmAdo et al. (2009), que analisaram dois Latossolos Vermelhos Distróficos nos municípios de Trindade do Sul e Palmeira das Missōes, no Rio Grande do Sul, em SD de milho e feijão irrigados por pivô central, e verificaram maior variabilidade nos dados de $\mathrm{P}$, e menor nos de $\mathrm{pH}$ do solo.

Quando uma variável estatística qualquer possuir distribuição de frequência do tipo normal, a medida de tendência central mais adequada para representá-la deve ser a média. Em contrapartida, será representada pela mediana, ou pela média geométrica, caso possua distribuição de frequência do tipo lognormal (MonTANARI et al., 2010). Desta forma, dentre os atributos analisados, observou-se distribuição de frequência do tipo normal em PG, pH, $\mathrm{Ca}, \mathrm{Mg}, \mathrm{S}, \mathrm{T}$ e V\%, sendo significativos pelo teste de normalidade de Shapiro e Wilk (1965), uma vez que seus valores oscilaram entre 0,050 e 0,838 (Tabela 1 ).

Analisando a tabela 1 é possível constatar ainda que o valor médio da PG foi de $3044 \mathrm{~kg} \mathrm{ha}^{-1}$. Este valor superou em $60 \%$ a produtividade de grãos de feijão de $1900 \mathrm{~kg}$ $\mathrm{ha}^{-1}$ obtida por Suzuki et al. (2007) e em $38 \%$ a de SANTOs et al. (2005), que relataram valor de $2208 \mathrm{~kg} \mathrm{ha}^{-1}$. Em relaçấo à média nacional $\left(913 \mathrm{~kg} \mathrm{ha}^{-1}\right)$, bem como à média do Mato Grosso do Sul (1456 kg ha-1), referidas pela ConAB (2010), os valores foram, respectivamente, $233 \%$ e $109 \%$ superior. Para Suzuki et al. (2003), esta considerável produtividade de grãos de feijão, possivelmente, está relacionada a $\mathrm{SD}$, que proporciona melhor armazenamento de água no solo bem como melhores condiçóes químicas para o suprimento da cultura.

Para os atributos químicos do solo, cuja distribuição de frequência foi do tipo normal, as médias obtidas foram 5,10;28,0 mmol $\mathrm{dm}^{-3} ; 18,0 \mathrm{mmol}_{\mathrm{c}} \mathrm{dm}^{-3} ; 51,20$ mmol $\mathrm{dm}^{-3} ; 78,40 \mathrm{mmol} \mathrm{dm}^{-3} ; 64,0 \%$ para $\mathrm{pH}, \mathrm{Ca}$, $\mathrm{Mg}, \mathrm{S}$, $\mathrm{T}$ e V\%, respectivamente (Tabela 1). Foi possível verificar ainda que os valores medianos da MO, $\mathrm{K}$ e $\mathrm{H}+\mathrm{Al}$, cuja distribuição de frequência foi do tipo indefinida, foram, respectivamente, $25,0 \mathrm{~g} \mathrm{dm}^{-3}, 5,00$ mmol $\mathrm{dm}^{-3}$ e $27,0 \mathrm{mmol}_{c} \mathrm{dm}^{-3}$ e para o P, com distribuição de frequência do tipo lognormal, a mediana obtida foi de $23,0 \mathrm{mg} \mathrm{dm}^{-3}$, podendo-se assim inferir que, na média, o solo estava em boas condições de fertilidade para cultivo de feijão de inverno (Ambrosano et al., 1996). Valores superiores, com exceção do K, foram obtidos por Cavalcante et al. (2007), na camada de 0-0,10 $\mathrm{m}$, que normalmente é a mais fértil quando comparada com a camada de 0-0,20 m, em um Latossolo Vermelho Distrófico típico argiloso sob SD há 20 anos, sendo: $42,4 \mathrm{~g} \mathrm{dm}^{-3}$ para a MO; 4,6 $\mathrm{mmol}_{\mathrm{c}} \mathrm{dm}^{-3}$ para o $\mathrm{K} ; 108,0 \mathrm{mmol}_{\mathrm{c}} \mathrm{dm}^{-3}$ para a $\mathrm{T}$ (valores médios) e mediana de $32,0 \mathrm{mg} \mathrm{dm}^{-3}$ para o $\mathrm{P}$.

Conforme a tabela 2, nas correlaçôes entre PG e os atributos do solo houve significância somente para os pares PG x MO $\left(r=0,212^{*}\right)$ e PG x pH $\left(r=0,295^{* *}\right)$. Para ambas as correlaçóes, o comportamento foi direto, indicando que com o aumento da $\mathrm{MO}$ e do $\mathrm{pH}$ haverá aumento da produtividade de grãos de feijão, fato interessante em $\mathrm{SD}$, haja vista que este sistema visa incrementar os teores de $\mathrm{MO}$, influenciando o $\mathrm{pH}$ do solo (Miyazawa et al., 2000). Reichert et al. (2008) também constataram correlação direta entre a produtividade de grãos e o pH na camada de $0-0,15 \mathrm{~m}$, onde o coeficiente de correlação foi de 0,697 , significativo a $1 \%$ de probabilidade, demonstrando ser a cultura do feijão suscetível à acidez do solo.

Tabela 2. Matriz de correlação linear entre a produtividade de grãos do feijão de inverno e de atributos químicos de um Latossolo Vermelho Distroférrico sob plantio direto

\begin{tabular}{|c|c|c|c|c|c|c|c|c|c|c|}
\hline \multirow{2}{*}{ Atributos } & \multicolumn{10}{|c|}{ Coeficiente de correlação ${ }^{(1)}$} \\
\hline & PG & $\mathbf{P}$ & MO & pH & $\mathbf{K}$ & $\mathrm{Ca}$ & Mg & $\mathrm{H}+\mathrm{Al}$ & $\mathbf{S}$ & $\mathbf{T}$ \\
\hline$P$ & $-0,140$ & & & & & & & & & \\
\hline MO & $0,212^{*}$ & 0,066 & & & & & & & & \\
\hline $\mathrm{pH}$ & $0,295^{* *}$ & $-0,143$ & $0,495^{* *}$ & & & & & & & \\
\hline K & 0,111 & $0,194^{*}$ & $0,280^{* *}$ & $0,190^{*}$ & & & & & & \\
\hline $\mathrm{Ca}$ & $-0,023$ & 0,076 & $0,338^{* *}$ & 0,141 & $0,385^{* *}$ & & & & & \\
\hline $\mathrm{Mg}$ & $-0,013$ & $-0,027$ & $0,339^{* *}$ & 0,164 & $0,282^{* *}$ & $0,902 * *$ & & & & \\
\hline $\mathrm{H}+\mathrm{Al}$ & $-0,072$ & $0,263^{* *}$ & $-0,170^{*}$ & $-0,798^{* *}$ & $-0,075$ & $-0,106$ & $-0,137$ & & & \\
\hline $\mathrm{S}$ & 0 & 0,052 & $0,370^{* *}$ & $0,180^{*}$ & $0,454^{* *}$ & $0,974 * *$ & $0,953^{* *}$ & $-0,133$ & & \\
\hline $\mathrm{T}$ & $-0,033$ & 0,144 & $0,311^{* *}$ & $-0,098$ & $0,424^{* *}$ & $0,915^{* *}$ & $0,889^{* *}$ & $0,211^{*}$ & $0,933^{* *}$ & \\
\hline V\% & 0,053 & $-0,071$ & $0,345^{* *}$ & $0,497^{* *}$ & $0,403^{* *}$ & $0,831^{* *}$ & $0,826^{* *}$ & $-0,568^{* *}$ & $0,857^{* *}$ & $0,629^{* *}$ \\
\hline
\end{tabular}

$\mathrm{PG}$ = produtividade de grãos do feijāo; $\mathrm{P}, \mathrm{MO}, \mathrm{pH}, \mathrm{K}, \mathrm{Ca}, \mathrm{Mg}, \mathrm{H}+\mathrm{Al}, \mathrm{S}, \mathrm{T}, \mathrm{V} \%$ são, respectivamente, fósforo, matéria orgânica, potencial hidrogeniônico, potássio, cálcio, magnésio, acidez potencial, soma de bases, capacidade de troca catiônica e saturaçâo por bases. ${ }^{(1) * *}$ significativo a $1 \%$, ${ }^{*}$ significativo a $5 \%$. 
Neste contexto, as correlaçóes entre os pares de atributos do solo do presente trabalho evidenciaram correlaçáo direta da $\mathrm{MO}$ com todos os demais $\left(\mathrm{r}=0,280^{* *} \mathrm{a}\right.$ $\left.0,495^{* *}\right)$, com exceção da $\mathrm{H}+\mathrm{Al}$, cuja correlação foi inversa $\left(r=-0,170^{*}\right)$ e com o $P$, que não apresentou correlação significativa (Tabela 2). É provável que, no solo cultivado por longo período no SD, as correlaçóes da $\mathrm{MO}$ com os demais atributos químicos do solo, se manifestem mais intensamente, influenciando a disponibilidade e a absorção de nutrientes e a produtividade das culturas (NICOLODI et al., 2008). Desta forma, pode-se afirmar que a matéria orgânica desempenha importante papel à sustentabilidade do sistema produtivo por ser um coloide orgânico responsável por boa parte da $\mathrm{T}$ do solo.

Para as correlaçóes entre os atributos das plantas $\mathrm{x}$ solo (Tabela 2), os modelos matemáticos $P G=f(p H)$ e $\mathrm{MO}=\mathrm{f}(\mathrm{pH})$, observou-se variação direta entre causa e efeito, sendo os modelos do tipo linear e potencial, com coeficientes de correlaçáo de $0,295^{* *}$ e $0,506^{* *}$ respectivamente (Figura 2a,b). A ausência de correlação entre PG x $S(r=0)$ pode ter ocorrido em virtude de o experimento ter sido desenvolvido em área sob pivô central, cujas bases $\mathrm{Ca}, \mathrm{Mg}$ e $\mathrm{K}$ não têm limitação em sua disponibilidade para a cultura do feijoeiro, pois estavam prontamente disponíveis na soluçấo do solo e em quantidades equilibradas para essa cultura.

$\mathrm{Na}$ análise de regressão múltipla da PG, em função de todos os atributos do solo, o modelo testado (Equação 3) explicou aproximadamente $22 \%$ da variação da produtividade de grãos de feijão $\left(\mathrm{r}^{2}=0,221^{* *}\right)$.
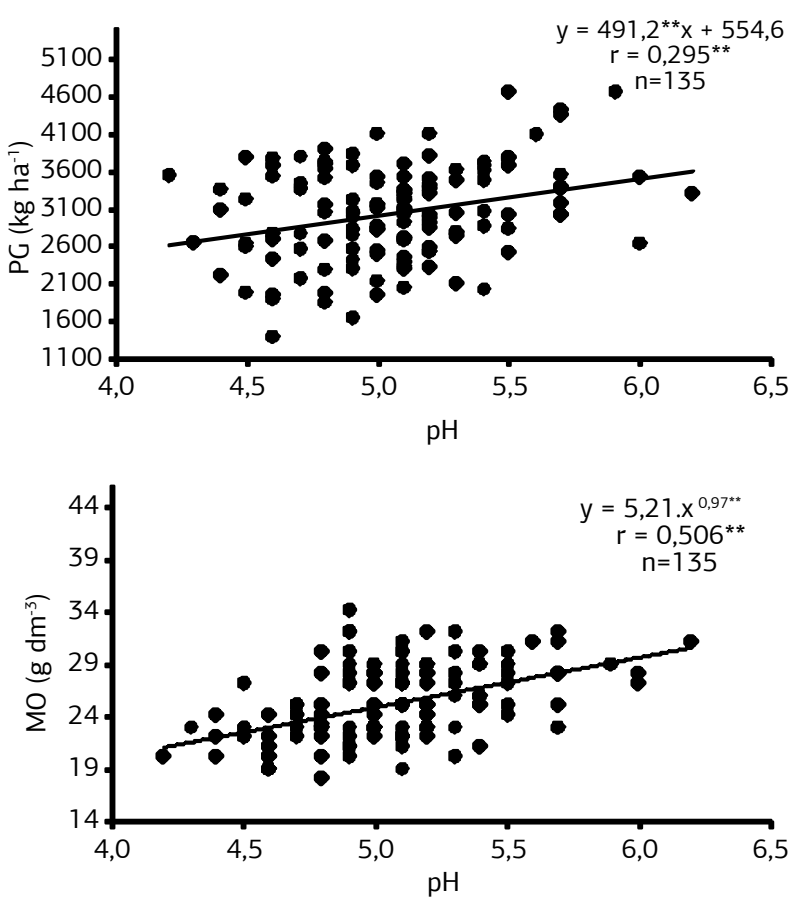

Figura 2. Equaçôes de regressão da produtividade de grãos de feijão de inverno e do teor de matéria orgânica do solo em função do $\mathrm{pH}$ de um Latossolo Vermelho Distroférrico sob plantio direto.
$\mathrm{PG}=-7,62 \cdot 10^{3}-6,88(\mathrm{P})-2,80(\mathrm{MO})+1,19.10^{3}$

$(\mathrm{pH})-3,85(\mathrm{~K})-2,75.10(\mathrm{Ca})-4,07.10(\mathrm{Mg})+$

$8,73.10(\mathrm{H}+\mathrm{Al})-8,43(\mathrm{~S})+1,34(\mathrm{~T})+5,29.10(\mathrm{~V} \%)$

De acordo com a tabela 3, com exceção do P que proporcionou efeito pepita puro (heterogeneidade em funçáo de adubações antecedentes e baixa mobilidade do elemento no solo), todos os demais atributos tiveram dependência espacial. Assim, os coeficientes de determinação espacial $\left(\mathrm{r}^{2}\right)$ observados nos semivariogramas, decresceram na seguinte ordem: 1) K (0,963), 2) V\% $(0,942), 3) \mathrm{pH}$ $(0,936), 4)$ PG $(0,923), 5) \mathrm{T}(0,901), 6) \mathrm{Ca}(0,875), 7)$ $\mathrm{S}(0,861), 8) \mathrm{Mg}(0,855), 9) \mathrm{MO}(0,787)$ e 10$) \# \mathrm{H}+\mathrm{Al}$ $(0,752)$. Portanto, em vista de ter sido apresentada aleatoriamente a menor dispersão dos lags em torno do modelo exponencial ajustado, o melhor semivariograma foi o do $\mathrm{K}\left(\mathrm{r}^{2}=0,963\right)$, com ADE médio de $58,9 \%$ e alcance de 24,9 m. Cavalcante et al. (2007) também observaram que o $\mathrm{K}$ foi o elemento com o melhor ajuste semivariográfico $\left(\mathrm{ADE}=48 \%\right.$ e $\left.\mathrm{r}^{2}=0,963\right)$, porém o modelo do semivariograma (esférico) e o alcance $(10,8 \mathrm{~m})$ obtidos diferiram desta pesquisa.

Para a saturação por bases (V\%), seu $\mathrm{r}^{2}(0,942)$ indicou ser o segundo atributo de melhor ajuste semivariográfico, com ADE média (70,9\%), semelhante ao de AMADo et al. (2009), porém com modelo ajustado do tipo esférico, diferindo do modelo gaussiano obtido neste trabalho, cujo alcance foi de $15,1 \mathrm{~m}$ (Tabela 3). $\mathrm{O}$ pH foi o terceiro atributo do solo com melhor ajuste do semivariograma $\left(r^{2}=0,936\right)$, com ADE de 76,7\% (alta), modelo esférico (Tabela 3; Figura 3c) e alcance de 25,8 m, concordando com AMADo et al. (2009), que também obtiveram modelo esférico e uma dependência espacial alta $(\mathrm{ADE}=88 \%)$. O quarto melhor ajuste semivariográfico foi o da PG, cujo $\mathrm{r}^{2}$ foi 0,923 . O modelo do semivariograma ajustado foi o exponencial (Tabela 3; Figura 3a) com ADE de 55,3\%, sendo, portanto classificado como atributo de média dependência espacial e alcance de $28,5 \mathrm{~m}$, discordando de Martins et al. (2009) que relataram um ajuste semivariográfico do tipo esférico para a produtividade do feijão cultivado em SD emm Latossolo Vermelho Distroférrico e alcance de $17,8 \mathrm{~m}$.

Ainda na tabela 3 é possível observar que a relação decrescente dos alcances foi a seguinte: 1$) \mathrm{T}(38,8 \mathrm{~m})$, 2) $\mathrm{PG}(28,5 \mathrm{~m}), 3) \mathrm{pH}(25,8 \mathrm{~m}), 4) \mathrm{K}(24,9 \mathrm{~m}), 5)$ $\# \mathrm{H}+\mathrm{Al}(17,0 \mathrm{~m}), 6) \mathrm{Mg}(16,0 \mathrm{~m}), 7) \mathrm{V} \%(15,1 \mathrm{~m}), 8)$ MO (14,1 m), 9) Ca (13,7 m) e 10) S (13,0 m). Esse resultado leva à sugestáo de que em trabalhos futuros, que utilizem malhas geoestatisticas e distância entre pontos iguais aos do presente, os valores dos alcances a serem utilizados nos pacotes geoestatísticos, que alimentarão os pacotes computacionais empregados na agricultura de precisão, em geral, deverão estar compreendidos entre $13,0 \mathrm{~m}$ e $38,8 \mathrm{~m}$, por representarem a distância dentro 
Tabela 3. Parâmetros dos semivariogramas ajustados para a produtividade do feijão de inverno e de atributos químicos de um Latossolo Vermelho Distroférrico sob plantio direto

\begin{tabular}{|c|c|c|c|c|c|c|c|c|c|c|c|}
\hline \multirow{3}{*}{ Atributo } & \multicolumn{11}{|c|}{ Parâmetros do ajuste } \\
\hline & \multirow{2}{*}{ Modelo } & \multirow{2}{*}{$C_{o}$} & \multirow{2}{*}{$\mathrm{C}_{\mathrm{o}}+\mathrm{C}$} & \multirow{2}{*}{$A_{o}(m)$} & \multirow{2}{*}{$\mathbf{r}^{2}$} & \multirow{2}{*}{ SQR } & \multicolumn{2}{|c|}{ ADE } & \multicolumn{3}{|c|}{ Validação cruzada } \\
\hline & & & & & & & $\%$ & Classe & a & b & $\mathbf{r}$ \\
\hline \multicolumn{12}{|c|}{$\mathrm{Y}(\mathrm{h})$ simples - planta } \\
\hline PG & $\exp (816)$ & $1,46.10^{5}$ & $3,27.10^{5}$ & 28,5 & 0,923 & $5,54.108$ & 55,3 & média & $-4,00$ & 1,002 & 0,467 \\
\hline \multicolumn{12}{|c|}{$y(h)$ simples - solo } \\
\hline $\mathrm{P}$ & epp & $3,19.10^{2}$ & - & - & - & - & - & - & - & - & - \\
\hline MO & gau (381) & 3,33 & 8,98 & 14,1 & 0,787 & 3,45 & 62,9 & média & $-0,39$ & 1,005 & 0,603 \\
\hline $\mathrm{pH}$ & esf (339) & $2,40.10^{-2}$ & $1,03.10^{-1}$ & 25,8 & 0,936 & $2,42.10^{-4}$ & 76,7 & alta & 0,54 & 0,892 & 0,585 \\
\hline K & $\exp (298)$ & 1,38 & 3,36 & 24,9 & 0,963 & $4,59 \cdot 10^{-2}$ & 58,9 & média & 1,19 & 0,753 & 0,295 \\
\hline $\mathrm{Ca}$ & esf (208) & $1,01.10$ & $7,04.10$ & 13,7 & 0,875 & $1,84.10^{2}$ & 85,7 & alta & $-0,29$ & 0,999 & 0,577 \\
\hline $\mathrm{Mg}$ & gau (375) & 8,54 & $2,32.10$ & 16,0 & 0,855 & $2,06.10$ & 63,2 & média & 1,03 & 0,939 & 0,524 \\
\hline$\# \mathrm{H}+\mathrm{Al}$ & gau (324) & $1,07.10$ & $2,14.10$ & 17,0 & 0,752 & $2,53.10$ & 50,0 & média & 0,31 & 1,000 & 0,436 \\
\hline$S$ & gau (138) & $3,99.10$ & $2,04.10^{2}$ & 13,0 & 0,861 & $3,48.10^{3}$ & 80,4 & alta & 1,43 & 0,964 & 0,593 \\
\hline $\mathrm{T}$ & esf (145) & $8,81.10$ & $1,94.10^{2}$ & 38,8 & 0,901 & $1,62.10^{3}$ & 54,6 & média & $-0,37$ & 1,002 & 0,596 \\
\hline V\% & gau (275) & $2,00.10$ & $6,68.10$ & 15,1 & 0,942 & $8,70.10$ & 70,9 & média & $-3,47$ & 1,047 & 0,645 \\
\hline \multicolumn{12}{|c|}{$y(h)$ cruzado - planta $x$ solo } \\
\hline$P G=f(M O)$ & gau (259) & 1,00 & $3,82 \cdot 10^{2}$ & 26,0 & 0,689 & $6,75.10^{-4}$ & 99,7 & alta & $9,68.10^{2}$ & 0,685 & 0,487 \\
\hline$P G=f(p H)$ & gau (532) & $1,00.10^{-1}$ & $6,31.10$ & 28.8 & 0,925 & $3,60.10^{2}$ & 99,8 & alta & $9,57.10^{2}$ & 0,685 & 0,482 \\
\hline \multicolumn{12}{|c|}{$y(h)$ cruzado - solo $x$ solo } \\
\hline $\mathrm{MO}=\mathrm{f}(\mathrm{pH})$ & gau (318) & $2,00.10^{-3}$ & $4,77.10^{-1}$ & 18,0 & 0,806 & $2,96.10^{-2}$ & 99,6 & alta & 5,18 & 0,793 & 0,610 \\
\hline
\end{tabular}

$\mathrm{PG}=$ produtividade de grãos de feijão, $\mathrm{P}=$ fósforo, $\mathrm{MO}=$ matéria orgânica, $\mathrm{pH}=$ potencial hidrogeniônico, $\mathrm{K}=$ potássio, $\mathrm{Ca}=$ cálcio, $\mathrm{Mg}=$ magnésio, \# $\mathrm{H}+\mathrm{Al}=$ acidez potencial, $\mathrm{S}=$ soma de bases, $\mathrm{T}$ = capacidade de troca de cátions e $\mathrm{V} \%$ = saturaçáo por bases; parênteses sucedendo o modelo = número de pares no primeiro lag. exp = exponencial; epp = efeito pepita puro; gau = gaussiano e esf = esférico. $\mathrm{SQR}=$ soma dos quadrados dos resíduos. $\mathrm{ADE}=$ avaliador da dependência espacial.

(a)

PG

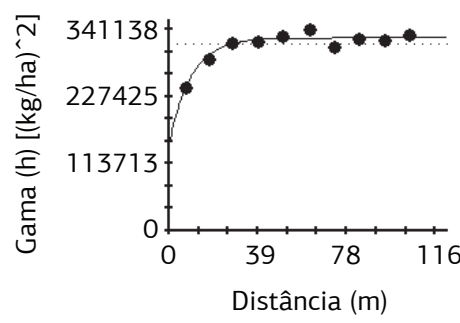

(c)

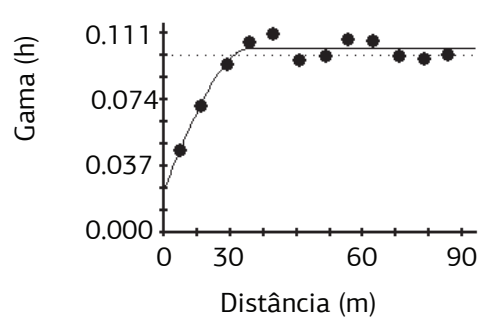

(b)
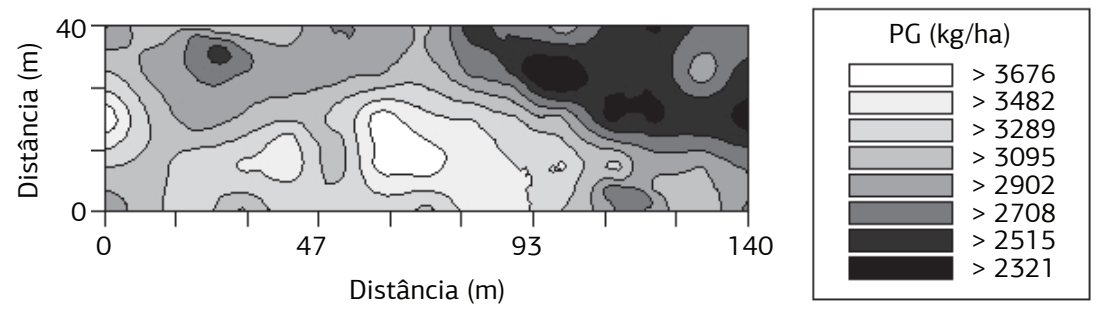

(d)

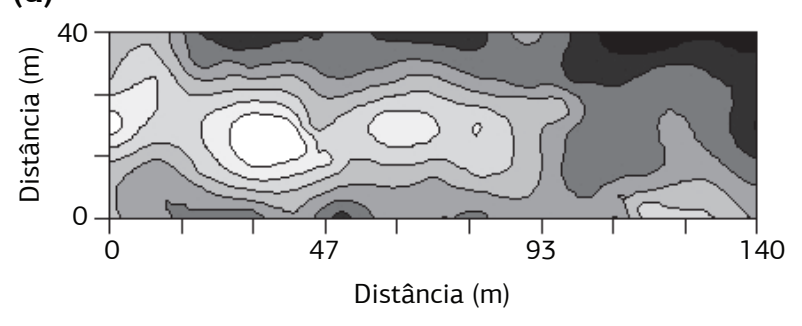

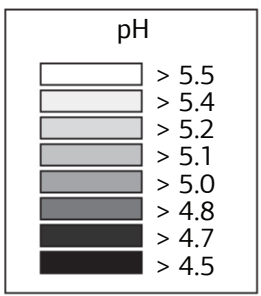

Figura 3. Semivariogramas e mapas de krigagem da produtividade do feijão de inverno e do $\mathrm{pH}$ de um Latossolo Vermelho Distroférrico sob plantio direto.

da qual os valores de um determinado atributo são iguais entre si.

$\mathrm{Na}$ figura $3 \mathrm{~b}$, visualiza-se no mapa de krigagem que os maiores valores da PG (3095 a $3676 \mathrm{~kg} \mathrm{ha}^{-1}$ ) ocorreram no sentido Centro-Oeste, bem como nas regióes Sudoeste, Sul e Sudeste, estabelecidas no terço horizontal inferior. Nas demais regióes (Leste e travessão horizontal superior) a produtividade oscilou entre 2321 e $3095 \mathrm{~kg} \mathrm{ha}^{-1}$. Foi evidenciada a semelhança direta entre os mapas de krigagem da PG e do pH (Figura 3b,d). Assim, nos sítios onde ocorreram os maiores valores de $\mathrm{pH}(5,1$ a 5,5), no sentido Centro-Oeste e região Sudeste do mapa, foram justamente os locais onde também ocorreram as maiores PGs (3095 a $3676 \mathrm{~kg} \mathrm{ha}^{-1}$ ). 
(a)

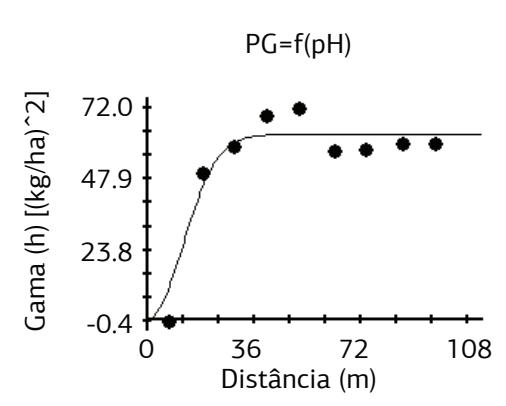

(b)

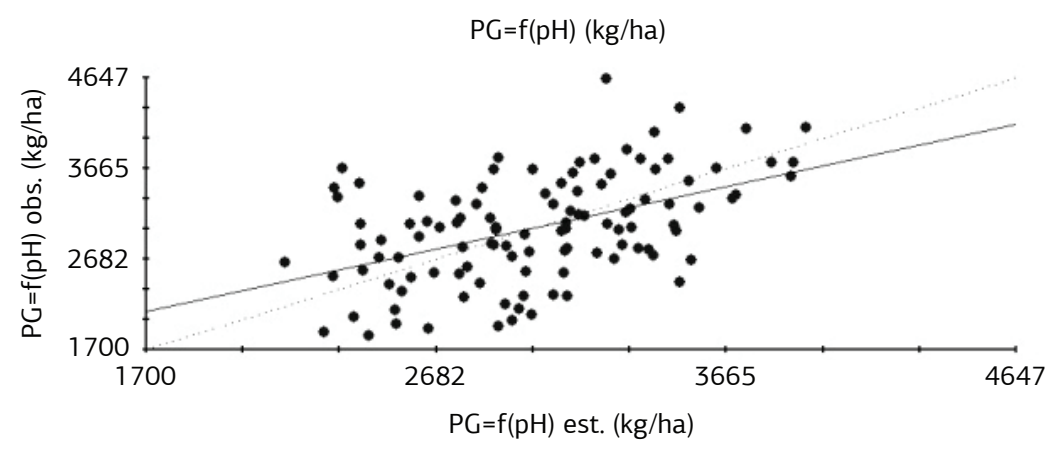

(c)
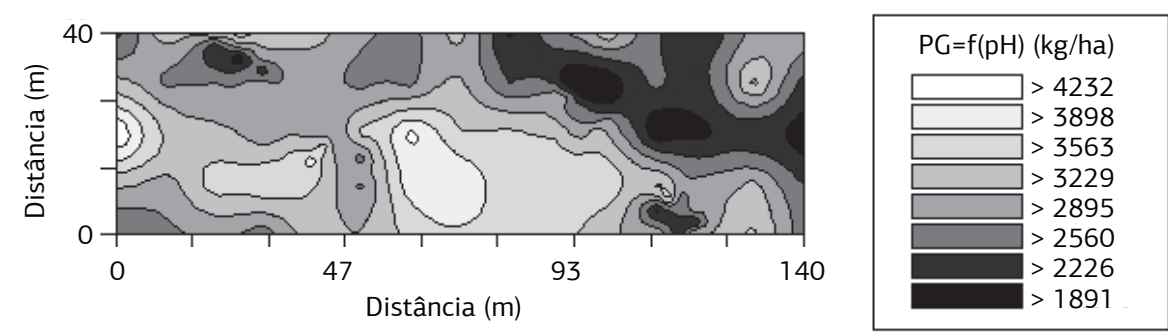

Figura 4. Semivariograma cruzado, validaçáo cruzada e mapa de co-krigagem da produtividade do feijão de inverno em função do pH de um Latossolo Vermelho Distroférrico sob plantio direto.

Por outro lado, nas demais regióes, com os menores valores de $\mathrm{pH}(4,5$ a 5,1$)$, ocorreram as menores PGs (2321 e $3095 \mathrm{~kg} \mathrm{ha}^{-1}$ ), demonstrando ser o feijoeiro sensível ao $\mathrm{pH}$ do solo.

Em termos de co-krigagem, o melhor ajuste foi entre PG e $\mathrm{pH}$, seguido da $\mathrm{MO}$ e $\mathrm{pH}\left(\mathrm{r}^{2}=0,806\right)$ e da PG e MO $\left(r^{2}=0,689\right)$ (Tabela 3). Rachid Junior et al. (2006) também constataram co-krigagens entre os dados de PG com pH e PG com MO. No caso da PG e $\mathrm{pH}, 92,5 \%$ da variabilidade espacial da produtividade de feijáo puderam ser explicados pela variabilidade espacial do $\mathrm{pH}$, de forma que os maiores valores de produtividade de feijão foram registrados justamente nas regiōes com maiores valores de $\mathrm{pH}$ (Figura 4c). A dependência espacial para esta co-krigagem foi alta $(\mathrm{ADE}=99,8 \%)$, sendo ajustado o modelo do tipo gaussiano (Tabela 3; Figura 4a) com o alcance de $28,8 \mathrm{~m}$. Dados semelhantes de co-krigagem da PG e pH também foram relatados por RACHID Junior et al. (2006), onde o ADE foi alto $(96,4 \%)$, com alcance de $21,5 \mathrm{~m}$ e ajuste do modelo do tipo esférico.

Assim, pode-se inferir que a variabilidade espacial entre os atributos $\mathrm{pH}$ e $\mathrm{MO}$ do solo com a produtividade de grãos de feijão seguiram o mesmo comportamento linear; portanto, pela co-krigagem de alta significância, pode-se estimar a produtividade do feijão pelo efeito direto do aumento do $\mathrm{pH}$ e do teor de $\mathrm{MO}$ do solo na camada de 0-0,20 m em solo de Cerrado.

\section{CONCLUSÃO}

Para a produtividade de grãos de feijão de inverno, a análise de regressão múltipla indica que $22 \%$ de sua variação é atribuída à variação nos atributos químicos do solo ( $\mathrm{P}$, $\mathrm{MO}, \mathrm{pH}, \mathrm{K}, \mathrm{Ca}, \mathrm{Mg}, \mathrm{H}+\mathrm{Al}, \mathrm{S}, \mathrm{T}$ e V\%).

Os atributos químicos têm dependência espacial classificada como média e alta, com modelo dos semivariogramas ajustados predominantemente do tipo gaussiano.

Tanto linear quanto espacialmente, o $\mathrm{pH}$ do solo se destaca como um potencial indicador da produtividade de grãos de feijão quando cultivado sob sistema plantio direto.

\section{REFERÊNCIAS}

AMADO, T.J.C.; PES, L.Z.; LEMAINSKI, C.L.; SCHENATO, R.B. Atributos químicos e físicos de Latossolos e sua relação com os rendimentos de milho e feijão irrigados. Revista Brasileira de Ciência do Solo, v.33, p.831-843, 2009.

AMBROSANO, E.J. TANAKA, R.T. MASCARENHAS, H.A.A. Leguminosas e Oleaginosas. IN: RAIJ, B. van.; CANTARELLA, H.; QUAGGIO, J.A.; FURLANI, A.M.C. Recomendação de adubação e calagem para o Estado de São Paulo. 2.ed. Campinas: Instituto Agronômico e Fundação IAC, 1996. p.189-204. (Boletim Técnico 100)

BARBOSA, G.F; ARF, O.; NASCIMENTO, M.S.; BUZETTI, S.; FREDDI, O.S. Nitrogênio em cobertura e molibdênio foliar no feijoeiro de inverno. Acta Scientiarum Agronomy, v.32, p.117-123, 2010. 
CAMBARDELLA, C.A.; MOORMAN, T.B.; NOVAK, J.M. PARKIN, T.B.; KARLEN, D.L.; TURCO, R.F.; KONOPKA, A.E. Field-scale variability of soil properties in Central Iowa soils. Soil Science Society of American Journal, v.58, p.1501-1511, 1994.

CANTARELLA, H.; RAIJ, B. van; COSCIONE, A.R.; ANDRADE, J.C. Determinação de alumínio, cálcio e magnésio trocáveis em extrato de cloreto de potássio. In: RAIJ, B. van; ANDRADE, J.C.; CANTARELLA, H.; QUAGGIO, J.A. (Ed.). Análise química para avaliação da fertilidade em solos tropicais. Campinas: Instituto Agronômico, 2001. 285p.

CAVALCANTE, E.G.S.; ALVES, M.C.; PEREIRA, G.T.; SOUZA, Z.M. Variabilidade espacial de MO, P, K e CTC do solo sob diferentes usos e manejos. Ciência Rural, v.37, p.394-400, 2007.

COMPANHIA NACIONAL DEABASTECIMENTO - CONAB. Acompanhamento da safra brasileira: grãos, décimo segundo levantamento, setembro 2010. Brasília: CONAB, 2010. 41p.

DALCHIAVON, F.C.; CARVALHO, M.P.; NOGUEIRA, D.C.; ROMANO, D.; ABRANTES, F.L.; ASSIS, J.T.; OLIVEIRA, M.S. Produtividade da soja e resistência mecânica à penetração do solo sob sistema plantio direto no cerrado brasileiro. Pesquisa Agropecuária Tropical, v.41, p.8-19, 2011.

DAVIS, J.C. Statistics and data analysis in geology. 2.ed. New York: John Wiley, 1986. 646p.

EMPRESA BRASILEIRA DE PESQUISA AGROPECUÁRIA EMBRAPA. Sistema brasileiro de classificação de solos (SiBCS). 2.ed. Rio de Janeiro: Embrapa Solos, 2006. 306p.

FAGERIA, N.K.; STONE, L.F. Produtividade de feijão no sistema plantio direto com aplicação de calcário e zinco. Pesquisa Agropecuária Brasileira, v.39, p.73-78, 2004.

GREGO, C.R.; VIEIRA, S.R. Variabilidade espacial de propriedades físicas do solo em uma parcela experimental. Revista Brasileira de Ciência do Solo, v.29, p.169-177, 2005.

GS ${ }^{+}$. Geostatistics for environmental sciences. 7.ed. Plainwell, Michigan: Gamma Design Software, 2004. 159p.

MARTINS, M.V.; CARVALHO, M.P.; ANDREOTTI, M.; MONTANARI, R. Correlação linear e espacial entre a produtividade do feijoeiro e atributos físicos de um Latossolo Vermelho Distroférrico de Selvíria, Estado de Mato Grosso do Sul. Acta Scientiarum Agronomy, v.31, p.147-154, 2009.

MIYAZAWA, M.; PAVAN, M.A.; FRANCHINI, J.C. Neutralização da acidez do perfil do solo por resíduos vegetais. Informaçôes Agronômicas, v.92, p.1-8, 2000.

MOLIN, J.P. Agricultura de precisão: fundamentos e estado atual da arte. In: CÂMARA, G.M. Soja: Tecnologia da
Produção II. Piracicaba: ESALQ, Departamento de Produção Vegetal, 2000. p.423-437.

MONTANARI, R.; CARVALHO, M.P.; ANDREOTTI, M.; DALCHIAVON, F.C.; LOVERA, L.H.; HONORATO, M.A.O. Aspectos da produtividade do feijáo correlacionados com atributos físicos do solo sob elevado nível tecnológico de manejo. Revista Brasileira de Ciência do Solo, v.34, p.1811-1822, 2010.

NICOLODI, M.; ANGHINONI, I.; GIANELLO, C. Indicadores da acidez do solo para recomendação de calagem no sistema plantio direto. Revista Brasileira de Ciência do Solo, v.32, p.237-247, 2008.

PIMENTEL-GOMES, F.; GARCIA, C.H. Estatística aplicada a experimentos agronômicos e florestais. 11.ed. Piracicaba: FEALQ, 2002. 309p.

RACHID JUNIOR, A.; URIBE-OPAZO, M.A.; SOUZA, E.G.; JOHANN, J.A. Variabilidade espacial e temporal de atributos químicos do solo e da produtividade da soja num sistema de agricultura de precisão. Engenharia na Agricultura, v.14, p.156-169, 2006.

REICHERT, J.M.; DARIVA, T.A.; REINERT, D.J.; SILVA, V.R. Variabilidade espacial de Planossolo e produtividade de soja em várzea sistematizada: análise geoestatística e análise de regressão. Ciência Rural, v.38, p.981-988, 2008.

SANTOS, P.A.; CARVALHO, M.P.; FREDDI, O.S.; KITAMURA, A.E.; FREITAG. E.E.; VANZELA, L.S. Correlação linear e espacial entre o rendimento de grâos do feijoeiro e a resistência mecânica a penetração em um Latossolo Vermelho distrófico. Revista Brasileira de Ciência do Solo, v.29, p.287-295, 2005.

SANTOS, R.L.L.; CORRÊA, J.B.D.; ANDRADE, M.J.B.; MORAIS, A.R. Comportamento de cultivares de feijoeiro-comum em sistema convencional e plantio direto com diferentes palhadas. Ciência e Agrotecnologia, v.28, p.978-989, 2004.

SCHLOTZHAVER, S.D.; LITTELL, R.C. SAS system for elementary statical analysis. 2.ed. Cary: SAS, 1997. 441p.

SHAPIRO, S.S.; WILK, M.B. An analysis of variance test for normality: Complete samples. Biometrika, v.52, p.591-611, 1965.

SUZUKI, L.E.A.S.; ALVES, M.C.; ENCIDE, A.P. Influência de plantas de cobertura, preparos do solo e sucessáo de culturas na produtividade de grãos de feijão em um Latossolo Vermelho de cerrado. Cultura Agronômica, v.12, p.1-16, 2003.

SUZUKI, L.E.A.S.; ALVES, M.C. ; SUZUKI, L.G.A.S. Rendimento do feijoeiro influenciado por sistemas de manejo em um Latossolo Vermelho de cerrado. Acta Scientiarum Agronomy, v.29, p.121-126, 2007.

VIANELLO, R.L.; ALVES, A.R. Meteorologia básica e aplicaçóes. Viçosa: Universidade Federal de Viçosa, 2004. 449p. 